\title{
Increasing of Electrical Energy with Solar Tracking System at the Region which Has Turkey's Most Solar Energy Potential
}

\author{
Musa Y1lmaz and Fevzi Kentli
}

\begin{abstract}
In this study, we investigated the efficiency of our own two-axis solar tracking photovoltaic system which designed by us according to a fixed system. The system's energy consumption was minimized by using tipper motor in the two-axis solar tracking system. Both systems were mounted in the same place to compare two-axis tracking system's efficiency with fixed system's efficiency fully and used the same breed panels, charge regulator, measurement device and battery. It was observed that Two-axis motion system efficiency was more than fixed system $31.67 \%$ over an annual average. This efficiency was measured on some days up to $70 \%$ during the winter months and up to $11 \%$ during the summer months.
\end{abstract}

Index Terms-Solar energy, photovoltaic, two axes sun tracking, Turkey solar energy.

\section{INTRODUCTION}

In 21st Century, Turkey has encountered serious energy problems which have led to use alternative energy resources. Also, the economic development depends on a reliable and sustainable energy provision as well-known. The reflections on environmental attitudes, especially for big cities across the country in the reduction of air pollution and global warming require the use of new technologies instead of using today's more polluting and less greenhouse gas-emitting energy sources, to reduce the world-wide risk of all expectations. One of the most important aspects of the energy source is the efficiency as well as the cost of its production [1]. Today, the sun solar panels used for generating electrical energy have come to a satisfactory level. They have the diversity of production and work on producing electrical energy from the unit surface. A power value is set for a certain number of solar panel which is connected serial/parallel to obtain the desired power [2]. However, if these panels achieve a more efficient energy, the cost reduces [3]. The studies on solar energy to generate electricity have increased in recent years. These studies have also examined efficiency on the effect of solar tracking systems [4].

Power of solar energy for the first time in Turkey was made

Manuscript received April 25, 2014; revised July 2, 2014. This project was supported by Dicle Üniversitesi Bilimsel Araştırma Projeleri Koordinatörlüğü (Dicle University of Scientific Research Projects Coordinator), (12-MYO-146).

Musa Yilmaz is with the Dicle University, Diyarbakir Technical Vocational School, Electrical and Energy Department, Diyarbakir, Turkey (e-mail: musayilmaz72@gmail.com, myilmaz@dicle.edu.tr).

Fevzi Kentli is with Marmara University, Faculty of Technology, Mechatronics Engineering, Goztepe Campus, Istanbul, Turkey (e-mail: fkentli@marmara.edu.tr). in a scientific research in 1970 by Turkish State Meteorological Service. The Turkish State Meteorological Service has the data related to the sunshine duration and solar radiation measured from 1966 to 1982 across Turkey. According to the General Directorate of Renewable Energy (EIE), the annual sunshine duration is 2640 hours (7.2hours), the maximum value of 361.8 hours of July and the minimum value observed in December, with 97.8 hours. The average intensity of total radiation is calculated as $1311 \mathrm{kWh} / \mathrm{m}^{2}$-year (3.6 $\left.\mathrm{kWh} / \mathrm{m}^{2}\right)$. The Southeastern Anatolia is the richest region with 3015.8 hours of sunshine in a year in terms of intensity [5].

In the study, a microcontroller-based two-axes sun tracking system which tracks the sun on both azimuth and altitude angles and which does not require photo sensors or pyranometers is developed in order to obtain the maximum energy from the sun. The azimuth and altitude angles are calculated by the microcontroller using the data on the latitude and longitude of the location of the PV panel. PWM signals that change based on the values of these angles are produced and used in order to control the DC motors. The study aims to present information about PV panels and sun tracking systems. The experimental results are obtained through the suggested system are presented.

In the present study, by the above-mentioned reasons and due to the highest solar energy potential of the Southeastern Anatolia Region, the energy potential of Diyarbakir, which is a city in the Southeastern Anatolia Region whose energy potential was measured as highest in Turkey is investigated in detail to achieve more significant results using solar tracking system involving PV panel that enables an important increase in the existing potential.

\section{DESIGN OF SOlaR TRACKING SySTEM}

Photovoltaic cells are devices that produce electricity directly from solar energy, which is among the renewable energy sources [2]. They are produced in different sizes and with different powers. The power that can be obtained is increased by connecting the panels in series or in parallel. The most important reason for preferring solar cells is that they benefit from a source which can be considered as infinite and they do not create waste material.

\section{A. Sun-Tracking Systems}

To obtain maximum energy from the solar panels, it is necessary that the rays of the sun fall vertically on the panel $[2]$. 
Various difficulties and inconveniences are encountered during the implementation of these systems. Tracking systems with photosensors necessitate the use of 4 different photosensors for two-axes tracking applications. Furthermore instabilities arise when one of the sensors is blocked or when the weather is partly cloudy.

Different control elements are used in control systems, such as microcontroller, PLC, microprocessors and other similar elements. Each of these control elements has specific programming methods.

In mechanical systems, the driver is selected based on the type of motor (DC motor, Step motor). Maximum energy cannot be fully obtained from the sun because of the operating principles of the motors used in the system. For example, in step motors, movement occurs in steps. Although the rays of the sun initially fall vertically on the panel, maximum energy cannot be obtained from systems with step motors because the solar azimuth angle changes within the time that passes until the step changes take place. In DC motors, on the other hand, it is necessary to use a separate circuit for changing the direction.

Because of the negative aspects and consequences presented above, an actuator motor which can track the instant changes in the angles of the sun and which can change the position and the angle of the system based on the control signals was used in the present study [6].

\section{B. Solar Angles}

In this section, it will be explained how to calculate the sun position at any time, at any location on any day of year. Firstly, it is accepted that (as ancient time) the earth is fixed and the sun spins around its north-south axis, after we must find the solar declination angle $(\delta)$. $\delta$ angle is between the plane of the equator and a line drawn from the center of the sun to the center of the earth. It varies between $+23.45^{\circ}$ and $-23.45^{\circ}$.

There are various formulas to find the declination angle but none of them can find exact values of declination, simply because $\delta$ varies slightly from year to year. One of them is

$$
\delta=\delta_{0} \operatorname{Sin}\left[360 \frac{(284+n)}{365}\right]
$$

where $n$ is the day number counted from the beginning of the year and $\delta_{\mathrm{o}}$ is $23.45^{\circ}$ [7].

Azimuth angle $\left(\varphi_{s}\right)$ is positive on east of south line and is negative on west of south line. Azimuth and altitude angle $(\beta)$ is found by means of the latitude, day number of the year and the time of the day. These angles can be found through the following formulas:

$$
\begin{gathered}
\sin (\beta)=\cos L \cos \delta \cos H+\sin L \sin \delta \\
\sin \varphi_{S}=\frac{\cos \delta \sin H}{\cos \beta}
\end{gathered}
$$

\section{EXPERIMENTAL RESULTS}

The experiment was conducted on the roof of one of the research facilities of Engineer faculty at Dicle University located in Diyarbakir $\left(37,91^{\circ} \mathrm{N}, 40,27^{\circ} \mathrm{E}\right)$.

Two polycrystalline PV module (Model DPE-120, Dunya Prestij Solar, GERMANY), each rating $120 \mathrm{~W}$ peak power, were used for the experiments. Table I shows the electrical parameters for the PV modules.

TABLE I: TYPICAL ELECTRICAL PARAMETERS FOR EXPERIMENTAL PV MODULES

\begin{tabular}{lcl}
\hline Peak power ${ }^{\mathrm{a}}(W p)$ & $\mathrm{W}$ & 120 \\
Open circuit voltage $\left(V_{\text {oc }}\right)$ & $\mathrm{V}$ & 32.89 \\
Max. power voltage $\left(V_{p m}\right)$ & $\mathrm{V}$ & 26.46 \\
Short circuit current $\left(I_{s c}\right)$ & $\mathrm{A}$ & 4.91 \\
Max. System Voltage & $\mathrm{V}$ & 1000 \\
Max. series fuse & $\mathrm{A}$ & 15 \\
\hline Standard test conditions (defined as: irradiance $=1000 \mathrm{~W} \mathrm{~m}^{-2} ;$ cell \\
temperature $=25^{\circ} \mathrm{C} ;$ AM 1.5G solar spectrum). \\
${ }^{\mathrm{a}}$ Rated power tolerance $\pm 5 \%$.
\end{tabular}

During the experiment, first PV panel $\left(\mathrm{PV}_{\mathrm{F}}\right)$ was mounted at a fixed tilt angle of $37^{\circ}$ facing true south (show Fig. 1), while two-axis solar tracking was applied to the second panels $\left(\mathrm{PV}_{\mathrm{T}}\right)$ following azimuth and altitude angles of the sun throughout the day [8].

To investigate the performance of the designed solar tracking system, a fixed system was established. Further, these systems were settled at the same roof to consider the same conditions imposed to the both two systems. Fig. 1 shows the picture of the two systems.

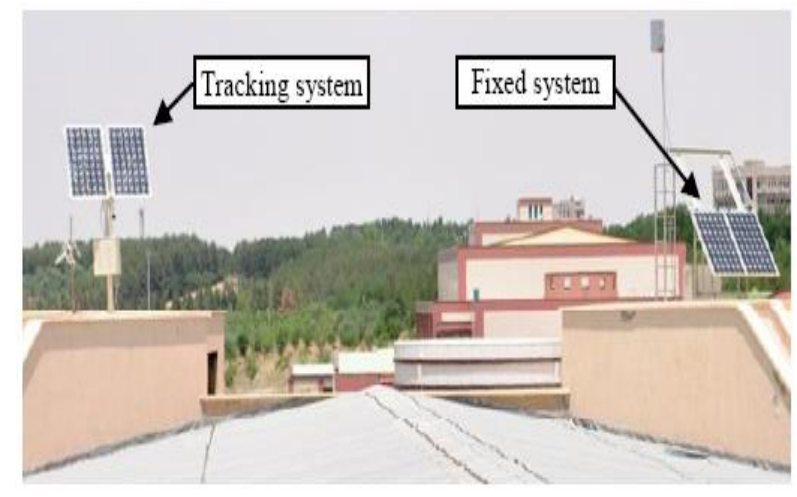

Fig. 1. View from the rooftop systems.

In order to move the panel on both axes, pins which were fixed to the panel and gears which were connected to these pins and other gears which were connected to the pins of the DC motors were used. The supply voltage of these DC motors is $24 \mathrm{~V} \mathrm{DC}$ [9].

In the designed system, the date and time information was collected in real time and transferred to the PIC 18F4520 microprocessor by using the DS1302 integrated circuit. The photo of two axis tracking array of the system is presented in Fig. 2.

The date and time data was read from the DS1302 and azimuth and slope angles were calculated by using the program in the PIC18F4520. Two PWM signals were produced by the PIC18F4520 based on the calculated values of the azimuth and slope angles. Voltages of $2-10 \mathrm{~V}$, which is the control signal of the motors, were obtained through driving the MOSFET with PWM signals and using the motors, the PV panel was rotated by the angle specified [2]. In the designed system, the PV panel was rotated according to the azimuth and the slope angles. 


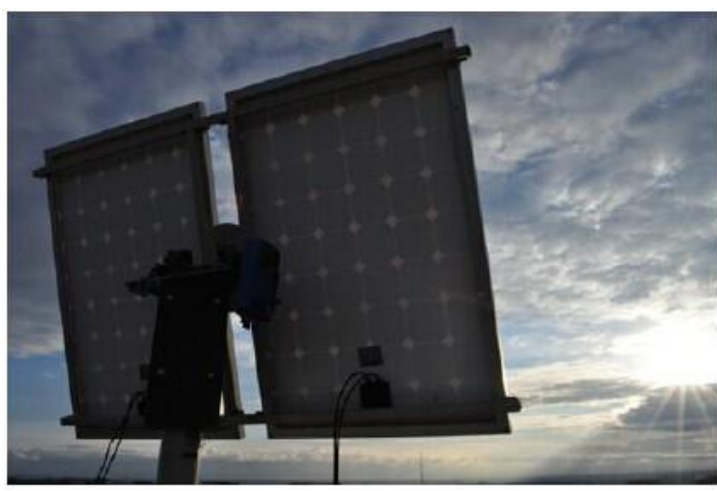

Fig. 2. The photo of tracking array.

The experiment is conducted on the roof of one of the research facilities of Diyarbakir Vocational College at Dicle University located in Diyarbakir $\left(37,91^{\circ} \mathrm{N}, 40,27^{\circ} \mathrm{E}\right)$ [8].

Diyarbakir utilizes solar energy for an average period of 7.91 hours. Since solar energy cannot be collected from the PV panel after this period of 7.91 hours, the PV panel is moved to the $0^{\circ}$ position and the system goes to stand-by mode until the sunrise. In this way, it is aimed to save energy and to decrease mechanical fatigue and wearing [10].

The voltage and power variation values obtained as the result of the motion of the PV panel through the sensor-based classical method and the voltage and power variation values obtained through rotating the panel by calculating the azimuth and slope angles without requiring sensors were compared [11]. In Fig. 3, it can be seen that more voltage is produced and more power is obtained by using the designed system compared to classical methods.

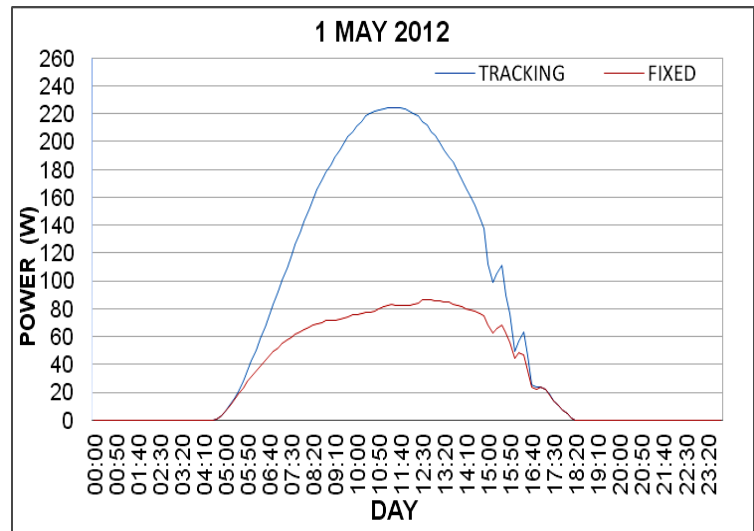

Fig. 3. Power value curve of the PV panel according to fixed position and sun tracking.

A low-cost and programmable system which tracks the sun on both azimuth and altitude angles in real time and which does not require photo sensors was developed in the present study [9]. The PV panel tracking system, which was developed as a microcontroller-based system, was tested in Diyarbakir province in Turkey and it was seen that more energy was obtained from the sun in the developed system when compared to fixed systems. Using the system developed in the present study, the sun was tracked in real time regardless of the weather being clear or overcast. In the experiments conducted on measurement months (Table II and Fig. 4.) it was observed that average $31.67 \%$ more energy was obtained when compared to fixed systems and since the tracking was performed in real time, no oscillation was observed in the energy obtained [12].

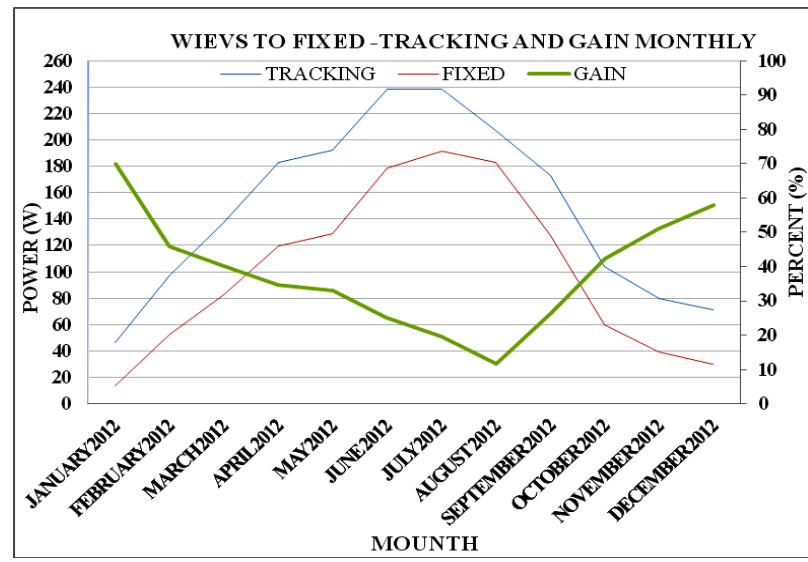

Fig. 4. Experimental average monthly total gain (\%).

TABLE II: EXPERIMENTAL AVERAGE DAILY TOTAL POWER (W)

\begin{tabular}{llll}
\hline Mounth & $\begin{array}{l}\text { Tracking }(\mathrm{W}) \\
\text { Power }\left(\mathrm{P}_{\mathrm{m}}\right) \mathrm{W}\end{array}$ & $\begin{array}{l}\text { Fixed }(\mathrm{W}) \\
\text { Power }\left(\mathrm{P}_{\mathrm{m}}\right) \mathrm{W}\end{array}$ & $\begin{array}{l}\text { \% Gain } \\
(\%)\end{array}$ \\
\hline January & 46,63306 & 13,957 & 70,07059 \\
February & 97,32637 & 52,68389 & 45,86884 \\
March & 137,5185 & 82,35492 & 40,11359 \\
April & 183,031 & 119,5477 & 34,68448 \\
May & 192,4453 & 128,7395 & 33,10332 \\
June & 238,376 & 178,7855 & 24,9985 \\
July & 238,151 & 191,715 & 19,49856 \\
August & 207,2755 & 183,2193 & 11,60591 \\
September & 172,9712 & 127,6538 & 26,19939 \\
October & 103,7979 & 59,84109 & 42,34847 \\
November & 80,05137 & 39,10646 & 51,14829 \\
December & 70,9503 & 29,95211 & 57,78438 \\
\hline Average & 147,4188 & 100,7207 & 31,67714 \\
\hline
\end{tabular}

\section{CONCLUSION}

In this study, the control and programming work in performance was observed in the new solar tracking system and according to the fixed system have achieved up to $46.93 \%$ to much more electrical energy during the winter months. Fixed solar panels were positioned on the $37^{\circ}$ south and the increase of tracking system efficiency during the summer months only $8.75 \%$ was the lowest level as seen in experimental. The heat and radiation reflection in the summer is the reason. Yet despite all this, an average of $32.84 \%$ percent gain, though the tracking system panel prices are high today, is an important gain. This study applied with the system was installed on the roof of Faculty of Engineering, in Dicle University, in Diyarbakir located in the sun belt in Turkey.

Turkey's most important solar energy potential of Southeast Anatolia Region is one of the provinces of Diyarbakir. For a year, the results of measurements for Diyarbakir which is one of the important provinces of Southeast Anatolia Region which has Turkey's the most solar energy potential have been gained to literature and various graphs were provided as daily, monthly and yearly based on annual data. In conclusion, in this study, a fixed system and two-axis solar tracking system which cost and power consumption were minimized were designed. Two systems were compared with each other according to various factors by taking annual measurements for the province of Diyarbakir. 
Turkey should increase solar energy works. Southeast region lands are very flat and wide, this is increased energy with by solar tracking system.

\section{REFERENCES}

[1] T. C. Akinci, E. Dursun, S. Seker, and O. Kilic, "Coherence analysis between hydrogen flow and electricity current in fuel cells," Ener. Educ. Sci. Tech.-A, vol. 28, pp. 555-562, 2012.

[2] C. Sungur, A. A. Altun, and H. Terzioglu, "A microcontroller-based real time two-axes sun tracking system for maximum PV energy," Ener. Educ. Sci. Tech.-A, vol. 28, pp. 827-834, 2012.

[3] Y. M. Chen, Y. C. Liu, S. C. Hung, and C. S. Cheng, "Multi-input inverter for grid-connected hybrid PV/wind power system," Power Electron IEEE Transac, vol. 22, pp. 1070-1077, 2007.

[4] A. Messai, A. Mellit, A. Guessoum, and S. A. Kalogirou, "Maximum power point tracking using a Ga optimized fuzzy logic controller and its FPGA implementation," Solar Energy, vol. 85, pp. 265-270, 2011.

[5] EIE. Publication of National Energy Conservation Center. (2012, October). [Online]. Available: http://www.eie.gov.tr.

[6] M. Ustuner and T. Ustuner, "The effects of temperature changes on efficiency of solar panels in different cities of Turkey," Ener. Educ. Sci. Tech.-A, vol. 28, pp. 631-640, 2012.

[7] S. Kivrak, "Comprehensive desing for controlling and modelling of an off-grid PV system at maximum power output," Ph.D. thesis, Dept. Energy Inst., Dokuz Eylul University, Izmir, 2008.

[8] M. Kacira, M. Simsek, Y. Babur, and S. Demirkol, "Determining optimum tilt angles and orientations of photovoltaic panels in Sanliurfa, Turkey," Renew Energy, vol. 29, pp. 1265-1275, 2004.

[9] C. Sungur, "Multi-axes sun-tracking system with PLC control for photovoltaic panels in Turkey," Renew Energy, vol. 4, pp. 1119-1125, 2009.

[10] I. Sefa, M. Demirtas, and D. Colak, "Application of one-axis sun tracking system," Energy Convers Manage, vol. 50, pp. 2709-2718, 2009.

[11] E. Dursun, M. Eroglu, S. Yazici, and O. Kilic, "Techno-economic analysis for a stand-alone hybrid power system: A case study, in Istanbul, Turkey," Ener. Educ. Sci. Tech.-A, vol. 28, pp. 1065-1078, 2012.
[12] F. Kentli and M. Yılmaz, "Obtaining the optimum efficiency electrical energy under Diyarbakir conditions using solar tracking system involving PV panel," Energy Education Science and Technology Part $A$, vol. 30, pp. 613-620, 2012.

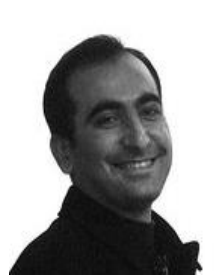

Musa Yılmaz was born in Batman, Turkey in 1979. $\mathrm{He}$ received the B.Sc., M.Sc. and Ph.D. degrees in electrical Edu. and Eng. from Abant İzzet Baysal Unv., Marmara Uni., Turkey, in 2001, 2004 and 2013, respectively. In 2001, he joined the Electrical Dept. of Düzce Tech. Teacher's Training College as a research. During 2003-2004, he has worked at the Energy Minister as an engineer. From 2004 to 2013, he worked at the Elec. Dept. of Dicle University as an instructor and a lecturer. Since 2013, he is working at the Electrical and Energy Dept. of Diyarbakir Technical Science Vocational School of Dicle Uni. as a Dr. His research interests are in the areas of electrical engineering educations, solar energy, solar tracking systems, photovoltaic panels and their controls and design.

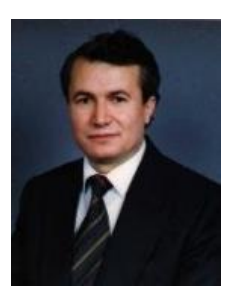

Fevzi Kentli was born in Isparta, Turkey in 1950. He received the B.Sc., M.Sc. and Ph.D. degrees in electrical Edu. and Eng. from Ankara Technical Teacher's Training College, Bosphorus Uni., Istanbul Technical Uni. and Marmara University, Turkey, in 1973, 1979, 1981 and 1992, respectively. In 1974, he joined the Electrical Dept. of Ankara Tech. Teacher's Training College as a research assistant. He was promoted to be an instructor and lecturer in 1981, Ass. Prof. in 1993. From 1981 to 1993, he worked at the Elec. Dept. of Ankara Tech. Teacher's Training College, Istanbul Tech. Teacher's Training College and Tech. Edu. Fac. of Marmara Uni. as an instructor and a lecturer. During 1993-2013, he has worked at the Elec. Edu. Dept. of Tech. Edu. Fac.of Marmara Uni. as an Ass. Prof. Since 2013, he is working at the Mechatronic Eng. Dept. of Technology Fac. of Marmara Uni. as an Assoc. Prof. His research interests are in the areas of electrical machines and their controls and design. 